\title{
CHONDROITIN SULFATE CONCENTRATION AND PROTEIN-POLYSACCHARIDE COMPOSITION OF ARTICULAR CARTILAGE IN OSTEOARTHRITIS *
}

\author{
By ALFRED JAY BOLLET, JOHN R. HANDY, AND BENJAMIN C. STURGILL \\ (From the Departments of Medicine, Preventive Medicine, and Pathology, University of Virginia \\ School of Medicine, Charlottesville, Va.)
}

(Submitted for publication November 19, 1962; accepted February 21, 1963)

In osteoarthritis the articular cartilage becomes roughened, fibrillar, softened, thinned, and finally eroded, with secondary changes occurring in the underlying bone. Histologically, early cartilage lesions in osteoarthritis are characterized by loss of metachromasia in the matrix, and it has been postulated that the initial disturbance involves the intercellular substance $(1,2)$. The decrease in metachromatic material in the matrix apparently is not due to degenerative changes in the cartilage cells ; on the contrary, areas of osteoarthritis usually show proliferation of chondrocytes and increased radiosulfate uptake (2). The loss of metachromasia has been attributed to a diminution in chondroitin sulfate content. Hirsch has shown a decreased sulfate concentration in chondromalacia of the patella, associated with loss of metachromatic staining and loss of elasticity of the cartilage (3). Matthews (4) reported a fall in hexosamine-hydroxyproline ratio in fibrillar osteoarthritic cartilage, and Kuhn and Leppelmann (5) showed a fall in galactosamine and glucosamine concentration of femoral articular cartilage in individuals with "arthrosis deformans." Such observations suggest that metabolic changes occur in the cartilage lesions of osteoarthritis.

In the studies to be reported, chondroitin sulfate concentration was determined as glucuronic acid, a more specific assay for this polysaccharide than hexosamine, since the latter is also present in the keratosulfate in cartilage ; for example, the hexosamine concentration of adult rib cartilage is four times greater than can be accounted for as chondroitin sulfate (6). A decrease in chondroitin sulfate concentration was found in osteoarthritic cartilage, most marked in the more advanced lesions. In addition, qualitative changes in the polysaccharide-protein complex of osteoarthritic cartilage

* Supported by U. S. Public Health Service research grant AM-03421 and training grant 2A-5233. were found, suggesting that polysaccharide breakdown was responsible for the decreased concentration of chondroitin sulfate.

\section{METHODS}

Articular cartilage was obtained from the knee and shoulder of 20 subjects 6 to 18 hours post-mortem. Knee cartilage was excised from the condylar surfaces of the femur or the posterior surface of the patella; in a few instances, samples were taken from the tibial plateau. Shoulder cartilage was taken from the anterior portion of the humeral head. Each sample was graded and processed separately. The degree of cartilage erosion in each area was quantitated on the basis of the smoothness of the surface, thickness, and consistency by the following criteria. Normal: Cartilage was smooth, white, glistening, and firm; pale yellow discoloration was occasionally present. Grade 1 osteoarthritis : Earliest lesions ; minimal pitting and fraying of the surface, sometimes visible only in strong light; normal consistency and thickness. Grade 2 osteoarthritis: Obvious irregularity of cartilage surface with pitting and fraying; some softening, but normal thickness. Grade 3 osteoarthritis: Extensive fraying and irregularity of surface; marked softening and some thinning of the cartilage. Grade 4 osteoarthritis: Erosion marked, with only a thin layer of soft, irregular cartilage remaining. The next grade was complete erosion of cartilage, exposing the underlying bone; therefore, no sample was obtainable for analysis.

Cartilage for chemical analysis was obtained by excision with a scalpel, with bone carefully excluded. In almost all instances, several specimens, including both normal and osteoarthritic cartilage, were obtained from each knee, at times from the same condyle. Samples for histologic study were taken from immediately adjacent areas of the same gross appearance with an electric saw; underlying bone was included for orientation. After at least 24 hours in $10 \%$ formaldehyde, these samples were embedded in paraffin, sectioned, and stained with hematoxylin and eosin, or toluidine blue.

The chondroitin sulfate and collagen concentrations of the cartilage were determined on dried, fat-free samples obtained after extraction of diced samples of cartilage in at least 50 vol of acetone for 18 hours. The dried samples were weighed with a Kahn electrobalance and hydrolyzed in $2 \mathrm{~N} \mathrm{HCl}$ for 2 hours at $100^{\circ} \mathrm{C}$. A sample of this hydrolyzed material was taken to determine uronic 
acid by the carbazole method of Dische (7) with minor modifications (8). The method used for glucuronic acid gave maximal yields from costal and articular cartilage, without interference from protein; commercial chondroitin sulfate subjected to the same procedure was recovered quantitatively. A separate sample of the acid-hydrolyzed cartilage was brought to $6 \mathrm{~N} \mathrm{HCl}$, hydrolyzed in an autoclave for an additional 6 hours at 15 pounds pressure, evaporated to dryness, and analyzed for hydroxyproline by the method of Kivirikko and Leismaa (9).

The cartilage polysaccharide-protein complex was isolated from fresh cartilage samples extracted in $100 \mathrm{vol}$ of water by the procedure of Malawista and Schubert (10). Extraction was initiated in a Servall Omnimixer at top speed for 15 minutes; the samples were then transferred to an Ultra-turrax model TP $18 / 2,1$ and homogenization was completed by two 1 -minute runs, with the containers kept immersed in ice. Longer periods of extraction did not increase the yield. After homogenization, the preparations were centrifuged at $35,000 \times g$ for 10 minutes at $0^{\circ} \mathrm{C}$. All subsequent centrifugation was done at the same speed, time, and temperature. Three vol of absolute ethanol were added to the supernatant fluid; after standing, centrifugation was repeated at this point, but no precipitate was found, and this step was discontinued. A 0.4 volume of $20 \%$ potassium acetate was added; after about 30 minutes at $0^{\circ} \mathrm{C}$, the resulting precipitate was recovered by centrifugation, dissolved in $5 \mathrm{ml}$ of water, and reprecipitated by addition of ethanol and potassium acetate in the same concentrations as above. The precipitate was then washed twice with a solution of water, ethanol, and potassium acetate in the same concentrations as for precipitation. After thorough decanting of the last wash, the precipitate was dissolved in $5 \mathrm{ml}$ of $0.5 \mathrm{~N}$ $\mathrm{NaOH}$, and samples were assayed for uronic acid by the carbazole method and for protein by the Folin-phenol method of Lowry, Rosebrough, Farr, and Randall (11), using a tyrosine standard. Protein values were expressed as "tyrosine equivalents."

The ratio of protein to polysaccharide in the original cartilage extract decreased after the first ethanol-potassium acetate precipitation; a further decrease occurred after the second precipitation, but no further change occurred when the material was redissolved and precipitated a third and fourth time. Two ethanol-potassium acetate precipitations were therefore used as the routine assay procedure. Electrophoresis of the original cartilage extract on cellulose acetate strips in barbital buffer, $\mathrm{pH}$ 8.6 and ionic strength 0.1 , showed movement of multiple protein bands on staining with nigrosin, but a single polysaccharide band on staining with toluidine blue. After two precipitations with ethanol, the extra protein bands were not detected; a single band containing both protein and polysaccharide moved from the origin, with some streaking of both components behind it. In addition, the material obtained by the first ethanol precipitate from normal cartilage was redissolved and reprecipitated with varying ethanol concentrations; the potassium concentration was kept constant. As the final ethanol concentration

1 Janke and Kunkel, Stauffen, Greisgau, Germany. was raised from 30 to $75 \%$, an increasing amount of both protein and polysaccharide was found in the precipitate; the ratio of the two in the various precipitates varied by no more than $15 \%$. As a routine procedure, $75 \%$ ethanol was used, as described for bovine nasal cartilage $(10,12)$.

\section{RESULTS}

Histologic observations. Sections taken from grossly normal articular cartilage were also normal microscopically, usually showing excellent preservation of the cartilage surface and an even distribution of cells within the matrix. Sections taken from areas of osteoarthritic erosion showed varying degrees of irregularity of the cartilage surface, with flaking of the superficial cartilage, fibrillation, and clumping of cells in the transitional zone. When simultaneous observations were made, a good correlation was found between the gross appearance of the cartilage and the severity of the microscopic changes. Toluidine blue stains showed loss of metachromasia of the matrix, most marked near the synovial surface, in osteoarthritic lesions. Even the most abnormal specimens showed good preservation of cellular detail, occasionally with a thin halo of metachromasia. Clumps of cells, apparently resulting from proliferation, were frequent in the osteoarthritic lesions. These observations are similar to those reported in previous studies of osteoarthritis (1, $2,13)$.

Chondroitin sulfate and collagen concentration in normal and osteoarthritic articular cartilage. Normal cartilage from different areas of the knee, including femoral condylar surfaces, tibial plateau, and posterior surface of the patella, showed similar chondroitin sulfate and collagen concentrations. The chondroitin sulfate concentrations found in normal articular cartilage from the shoulder and knee did not vary with age in the persons studied, who were almost all between 50 and 80 years old (Figure 1). The chondroitin sulfate concentration was higher in normal knee cartilage than in normal cartilage from the shoulder, but the collagen concentration was higher in the shoulder (Figure 2).

In the osteoarthritic cartilage, a decrease in chondroitin sulfate concentration was found, most marked in the more advanced lesions. The concentration of hydroxyproline was virtually unchanged in abnormal cartilage samples (Figure 2). 


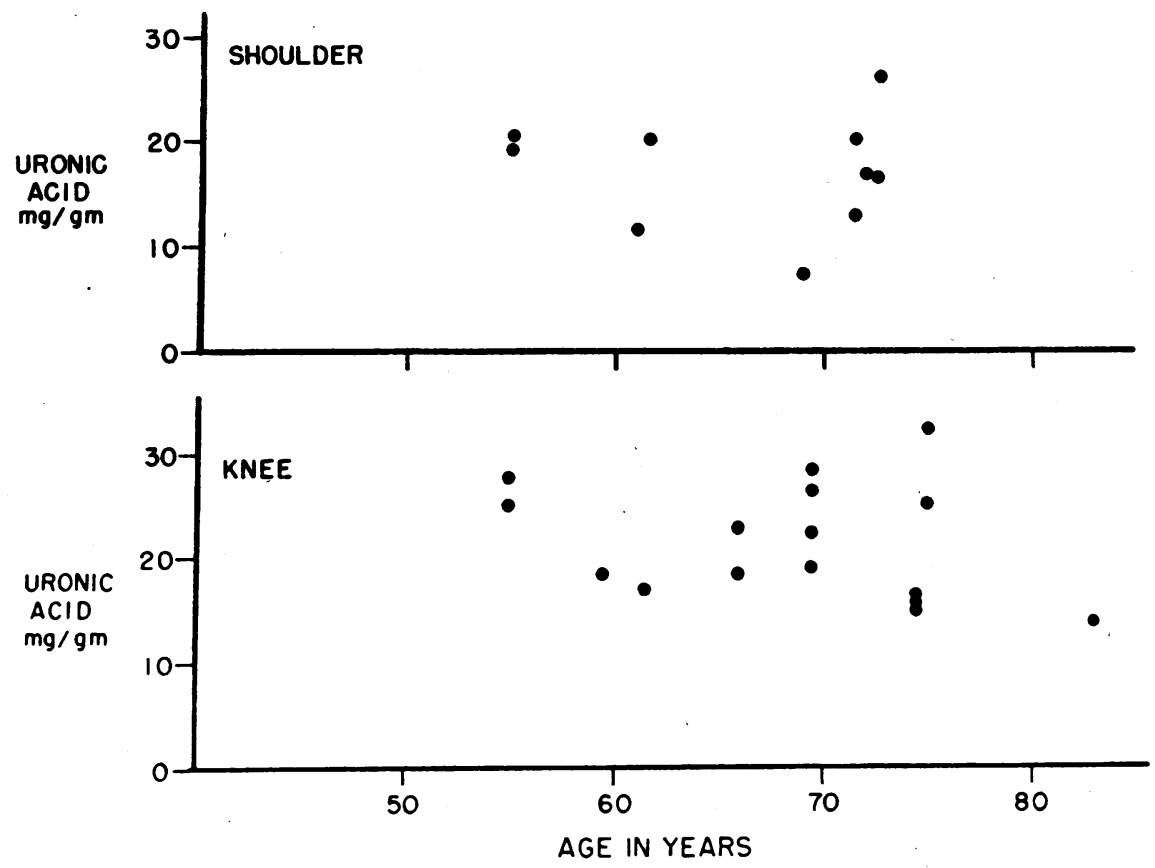

Fig. 1. Concentration of chondrottin sulfate (AS gLUCURONic ACID) IN NORMaL ARTICULAR CARTILAGE FROM THE SHOULDER AND KNEE AT VARIOUS AGES.

The ratio of chondroitin sulfate to collagen was thus decreased in the abnormal cartilage. The assignment of the grade of cartilage alteration was not thought sufficiently reproducible for statistical analyses; the data were therefore regrouped into three major categories. Grades 1 and 2 lesions were grouped as "early osteoarthritis," grades 3 and 4 as "advanced osteoarthritis," and these were compared to findings in normal knee cartilage. These calculations are summarized in Table I. The chondroitin sulfate concentration decreased by $27 \%$ in the early lesions and by $43 \%$ in the advanced lesions; both changes were statiśtically significant.

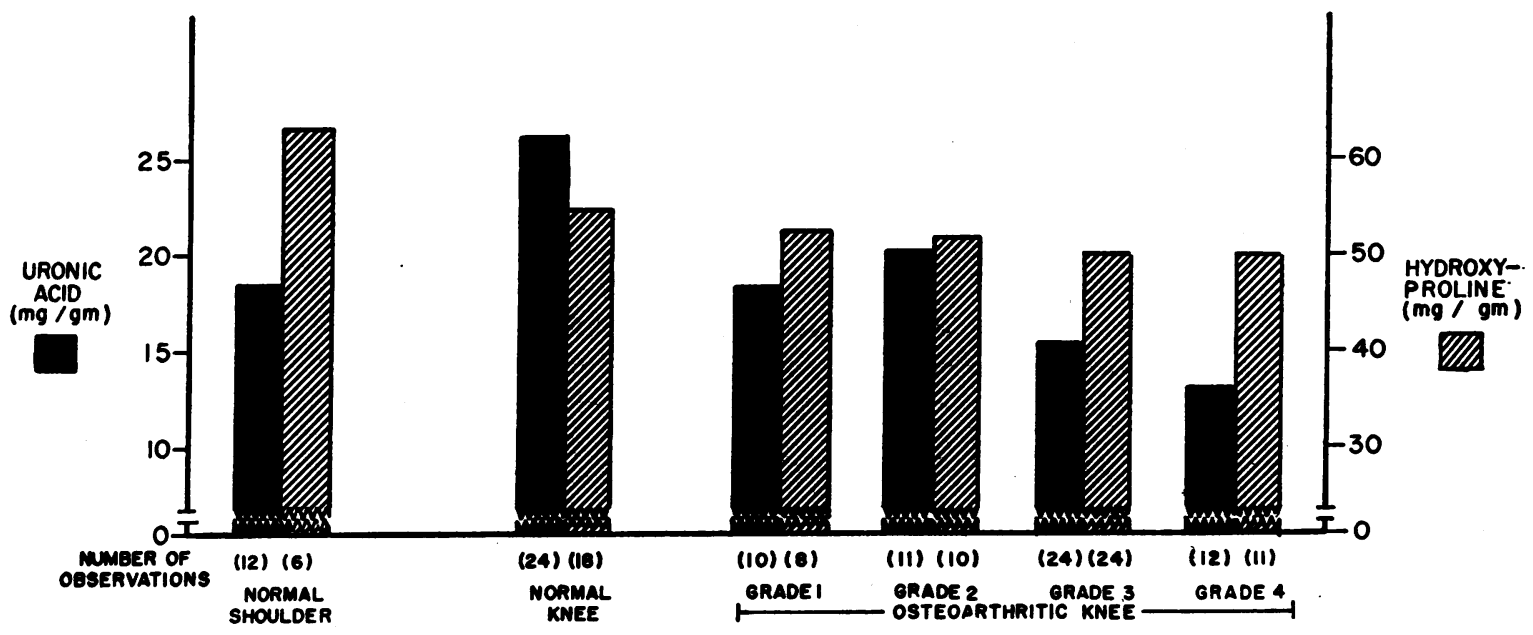

Fig. 2. CONCENTRATION OF CHONDROITIN SUlFATE (AS GLUCURONIC ACID) AND COLLAGEN (AS HYDROXYPROLINE) IN NORMAL AND OSTEOARTHRITIC ARTICULAR CARTILAGE. Values are in milligrams per gram of acetone-dried cartilage. 


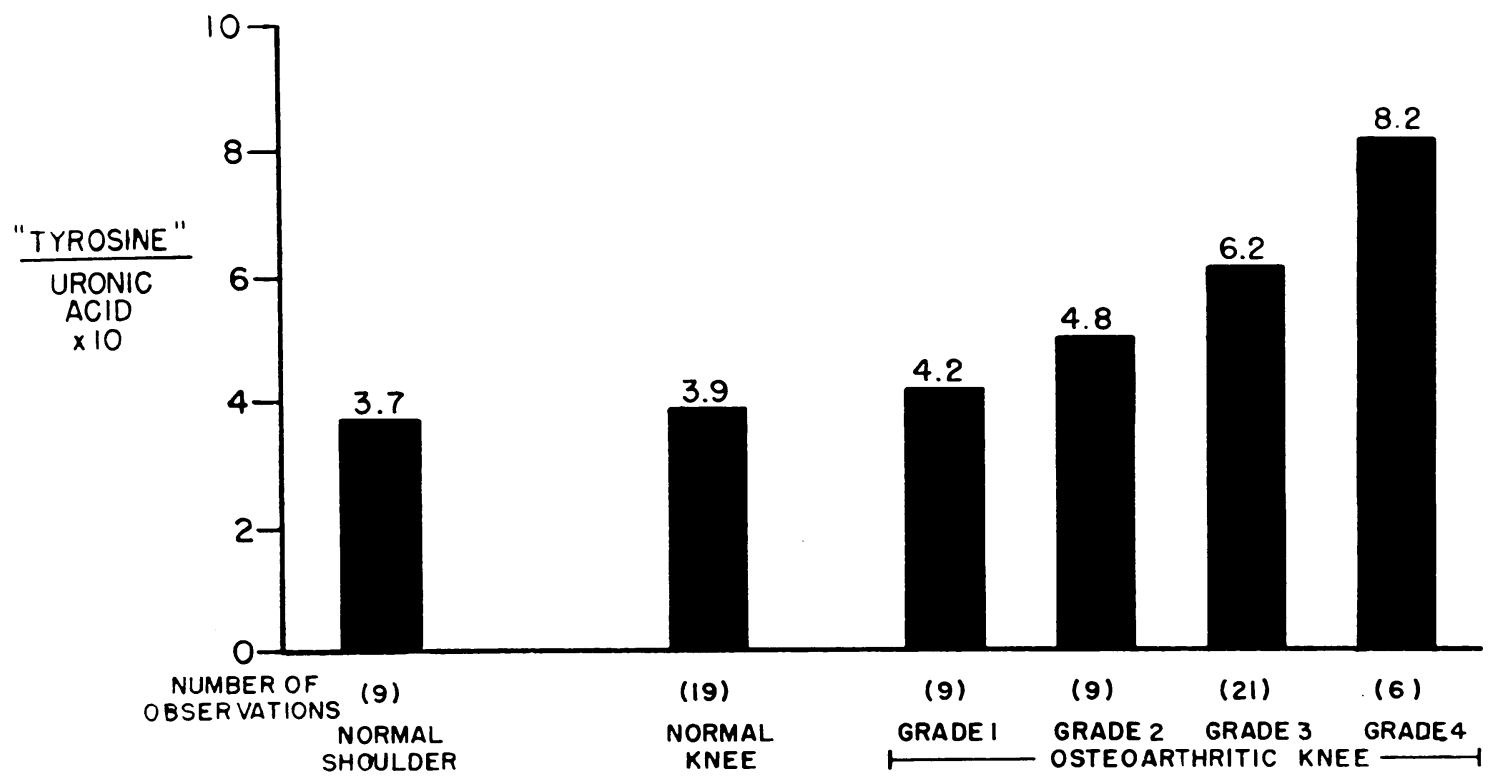

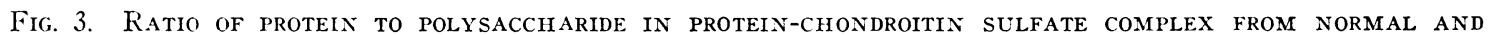
osteoarthritic cartilage. Protein is expressed in milligrams of "tyrosine equivalents," and chondroitin sulfate in milligrams of glucuronic acid.

Ratio of protcin to polysaccharide in the proteinchondroitin sulfate complex isolated from normal and osteoarthritic articular cartilage. The protein to polysaccharide ratio of the protein-chondroitin sulfate complex was increased slightly in the grades 1 and 2 osteoarthritic lesions; marked increases were found in the grades 3 and 4 lesions (Figure 3). Statistical evaluations were made on the basis of the three major groups described above; the increase in ratio found in the early

TABLE I

Concentration of polvsaccharide (measured as uronic acid) and collagen (measured as hydroxyproline) in normal and osteoarthritic articular cartilage*

\begin{tabular}{|c|c|c|c|c|}
\hline & \multirow[b]{2}{*}{$\begin{array}{l}\text { Cormal } \\
\text { shoulder }\end{array}$} & \multicolumn{3}{|c|}{ Knee } \\
\hline & & Normal & $\begin{array}{l}\text { Early } \\
\text { osteo- } \\
\text { arthritis }\end{array}$ & $\begin{array}{l}\text { Advanced } \\
\text { osteo- } \\
\text { arthritis }\end{array}$ \\
\hline \multicolumn{5}{|l|}{ Uronic acirl } \\
\hline Mean & 18.5 & 26.4 & 19.3 & 14.7 \\
\hline SEM & \pm 1.8 & \pm 2.3 & \pm 1.3 & \pm 1.4 \\
\hline No. of observations: & 12 & 24 & 21 & 36 \\
\hline $\mathrm{p}$ & 0.02 & & $<0.02$ & $<0.001$ \\
\hline \multicolumn{5}{|l|}{ Hydroxyproline } \\
\hline Mean & 63.4 & 54.9 & 52.3 & 50.0 \\
\hline $\mathrm{SEM}$ & $=2.4$ & \pm 2.6 & \pm 2.6 & \pm 2.1 \\
\hline No. of observations & 6 & 18 & 18 & 35 \\
\hline
\end{tabular}

* Concentration is in milligrams per gram of acetone-dried cartilage. SEM = standard error of mean. Values of $p$ are given only where significant difference from normal knee cartilage exists. osteoarthritic lesions was not statistically significant, but the change in the advanced lesions was highly significant (Table II).

The amounts of protein and polysaccharide found in the reprecipitated complex were calculated in relation to the weight of cartilage extracted. Since fresh cartilage samples were used to avoid changes in the complex during handling, differences in water content undoubtedly existed, and these data can be considered only an approximation of quantitative values. Comparison can be made, however, of the relative changes in concentration of the two components of the complex. The protein concentrations were not significantly decreased, but the polysaccharide concentrations

TABLE II

Ratio of protein to polysaccharide in cartilage proteinchondroitin sulfate in normal and osteoarthritic knee cartilage

\begin{tabular}{|c|c|c|c|}
\hline & Normal & $\begin{array}{c}\text { Early } \\
\text { osteo- } \\
\text { arthritis }\end{array}$ & $\begin{array}{l}\text { Advanced } \\
\text { osteo- } \\
\text { arthritis }\end{array}$ \\
\hline Ratio (mean) & 3.87 & 4.48 & 6.66 \\
\hline SEM & \pm 0.36 & 0.44 & \pm 0.38 \\
\hline No. of observations & 19 & 18 & $\begin{array}{r}27 \\
<\quad 0001\end{array}$ \\
\hline
\end{tabular}

* Value of $\mathrm{p}$ is given only where significantly different from normal. 
TABLE III

Concentration of chondroitin sulfate (as uronic acid) and protein (as "tryosine equivalents") in cartilage protein-polysaccharide complex*

\begin{tabular}{|c|c|c|c|c|}
\hline & \multirow[b]{2}{*}{$\begin{array}{l}\text { Normal } \\
\text { shoulder }\end{array}$} & \multicolumn{3}{|c|}{ Knee } \\
\hline & & Normal & $\begin{array}{c}\text { Early } \\
\text { osteoarthritis }\end{array}$ & $\begin{array}{c}\text { Advanced } \\
\text { osteoarthritis }\end{array}$ \\
\hline \multicolumn{5}{|l|}{ A. Uronic acid } \\
\hline $\begin{array}{l}\text { Mean } \\
\text { SEM } \\
\text { No. of observations } \\
\text { p }\end{array}$ & $\begin{array}{c}4.47 \\
\pm 0.41 \\
11 \\
<0.05\end{array}$ & $\begin{aligned} & 6.15 \\
& \pm 0.53 \\
& 19\end{aligned}$ & $\begin{array}{c}3.96 \\
\pm 0.34 \\
23 \\
<0.001\end{array}$ & $\begin{array}{c}2.95 \\
\pm 0.29 \\
27 \\
<0.001\end{array}$ \\
\hline \multicolumn{5}{|l|}{ B. Protein } \\
\hline $\begin{array}{l}\text { Mean } \\
\text { SEM } \\
\text { No. of observations } \\
\text { p }\end{array}$ & $\begin{array}{c}1.42 \\
\pm 0.11 \\
11 \\
<0.01\end{array}$ & $\begin{array}{c}2.22 \\
\pm 0.17 \\
19\end{array}$ & $\begin{array}{c}1.75 \\
\pm \quad 0.23 \\
23\end{array}$ & $\begin{array}{l}1.80 \\
0.15 \\
27\end{array}$ \\
\hline
\end{tabular}

* Concentration is expressed in milligrams per gram of fresh, wet cartilage. Values of $p$ are given only where significant difference from normal knee cartilage exists.

were markedly decreased in the osteoarthritic lesions (Table III). The increase in protein-polysaccharide ratio in the complex was therefore due to loss of polysaccharide.

\section{DISCUSSION}

The polysaccharides that have been identified in cartilage are the chondroitin sulfates $\mathrm{A}$ and $\mathrm{C}$, and keratosulfate. Keratosulfate, a polymer of glucosamine, galactose, and sulfate, did not influence the determinations used in this study. No distinction was made between chondroitin sulfates $\mathrm{A}$ and $\mathrm{C}$; both contain approximately $40 \%$ glucuronic acid, differing only in the location of the sulfate group on the galactosamine moiety, and therefore the term "chondroitin sulfate" has been used to indicate the total of both $\mathrm{A}$ and $\mathrm{C}$.

The chondroitin sulfate concentration of costal cartilage has been reported to fall with increasing age $(6,14)$. Kuhn and Leppelmann (15) found that the hexosamine and sulfur concentration of human distal femoral articular cartilage was relatively constant between the ages 20 to 90 years in the absence of "arthrosis deformans." In the present study no change in chondroitin sulfate concentration was found in normal knee or shoulder articular cartilage in the age range of 50 to 80 years; too few specimens were obtained below age 50 to permit statements concerning younger persons. The lack of correlation of chondroitin sulfate concentration with age in the range in which osteoarthritis occurs most frequently is notable, since it indicates that decreasing chondroitin sulfate concentration in cartilage is not an invariable complement of aging. The loss of polysaccharide from the cartilage may play a role in the pathogenesis of the gross as well as the microscopic changes in osteoarthritis, since the lesions could be attributed largely to changes in the physical properties of cartilage contributed by the polysaccharide (3). Collagen concentration remained virtually unchanged even in advanced osteoarthritis, suggesting that loss of the supporting properties of the collagen fibers was not a pathogenetic aspect of the lesions.

McElligott and Collins (16) and Collins and Meachim (17) have reported an increased radiosulfate fixation by chondrocytes in articular cartilage with increasing age; $S^{35}$ uptake was higher in areas of osteoarthritic cartilage than in normal articular cartilage taken from the same persons (2). The avidity for sulfate increased progressively with increased severity of the osteoarthritic process. Apparently, an increased rate of chondroitin sulfate synthesis occurs in osteoarthritic cartilage, and therefore it is necessary to postulate a greater increase in polysaccharide breakdown to account for the decreased chondroitin sulfate concentration.

The mechanism of breakdown of connective tissue polysaccharides has not been fully elucidated; enzymes such as proteases or hyaluronidases, or nonenzymatic factors could be responsible. Loss 
of chondroitin sulfate from cartilage as a result of proteolytic enzyme action was graphically demonstrated by Thomas's studies of the flop-eared rabbits resulting from papain administration (18). Tissue proteases, such as cathepsins, might be responsible for the relatively rapid polysaccharide turnover occurring in connective tissue normally or for the alterations occurring in disease. The relative amounts of the two components of the cartilage polysaccharide-protein complex were determined in the hope of finding a clue to the type of enzyme activity responsible for the increased turnover of polysaccharide in osteoarthritis. The increased ratio of protein to polysaccharide found suggests more rapid removal of the polysaccharide moiety from these complexes, pointing to the action of a hyaluronidase-like factor, rather than a protease.

To determine if breakdown of the cartilage chondroitin sulfate could give the changes in protein-polysaccharide ratio observed, aqueous extracts of articular cartilage were digested in vitro with testicular hyaluronidase ${ }^{2}$ or trypsin, and then precipitated with ethanol in the presence of potassium, by the same procedure used in the analyses of the cartilage samples. Trypsin digestion caused recovery of less protein, resulting in a decreased protein-polysaccharide ratio in the precipitated complexes. Hyaluronidase treatment caused recovery of less polysaccharide, resulting in increased protein-polysaccharide ratios, thus reproducing the findings made on the osteoarthritis cartilage.

Previous reports have emphasized that hyaluronidase is definitely present in one mammalian tissue, the testis; its presence in other tissues has been questioned (19). Reinvestigation of the distribution of hyaluronidase in various tissues was undertaken, and recent studies in our laboratory have revealed the presence of enzyme with characteristics resembling those of testicular hyaluronidase in kidney, spleen, liver, and lung in the rat. Hyaluronidase has also been found in human synovial tissue and synovial fluid, indicating that this type of enzyme may have access to articular cartilage and could play a role in the increased polysaccharide turnover occurring in osteoarthritic lesions.

\footnotetext{
2 Sigma Chemical Company, St. Louis, Mo.
}

\section{SUMMARY}

1. The chondroitin sulfate and collagen concentrations of human articular cartilage were determined on autopsy specimens. A decreased chondroitin sulfate concentration was found in osteoarthritic cartilage; the extent of the decrease was proportional to the severity of the osteoarthritic lesions. Collagen concentrations remained virtually unchanged.

2. The relative amount of the two components of the cartilage protein-polysaccharide complex was also determined. The ratio of protein to polysaccharide was increased in osteoarthritic cartilage, particularly in the advanced lesions, due to a fall in polysaccharide content.

3. Since others have reported increased radiosulfate uptake by chondrocytes in osteoarthritic lesions, the decreased concentration of chondroitin sulfate probably indicates excessive breakdown. The change in protein-polysaccharide ratio suggests that a hyaluronidase-like enzyme is responsible.

\section{ACKNOWLEDGMENT}

The authors wish to thank Dr. Leon Sokoloff for his guidance and assistance, and for providing the initial stimulus to undertake this study. Misses Joanne Nance and Jill Humphries also deserve thanks for expert technical assistance.

\section{REFERENCES}

1. Bennett, G. A., W. Bauer, and H. Waine. Changes in the Knee Joint at Various Ages. New York, Commonwealth Fund, 1942.

2. Collins, D. H., and T. F. McElligott. Sulphate $\left({ }^{35} \mathrm{SO}_{4}\right)$ uptake by chondrocytes in relation to histological changes in osteoarthritic human articular cartilage. Ann. rheum. Dis. 1960, 19, 318.

3. Hirsch, C. The pathogenesis of chondromalacia of the patella. A physical, histologic and chemical study. Acta chir. scand. 1944, 90, suppl. 83.

4. Matthews, B. F. Composition of articular cartilage in osteoarthritis. Changes in collagen chondroitinsulphate ratio. Brit. Med. J. 1953, 2, 660.

5. Kuhn, R., and H. J. Leppelmann. Der Hexosamingehalt des Knorpels in Abhängigkeit vom Lebensalter. Justus Liebigs Ann. Chem.1957, 607, 202.

6. Shetlar, M. R., and Y. F. Masters. Effect of age on polysaccharide composition of cartilage. Proc. Soc. exp. Biol. (N. Y.) 1955, 90, 31.

7. Dische, Z. A new specific color reaction of hexuronic acids. J. biol. Chem. 1947, 167, 189.

8. Bollet, A. J., M. W. Seraydarian, and W. F. Simpson. Acid mucopolysaccharides in normal serum. J. clin. Invest. 1957, 36, 1328. 
9. Kivirikko, K. I., and M. Liesmaa. A colorimetric method for determination of hydroxyproline in tissue hydrolysates. Scand. J. clin. Lab. Invest. 1959, 11, 128.

10. Malawista, I., and M. Schubert. Chondromucoprotein, new extraction method and alkaline degradation. J. biol. Chem. 1958, 230, 535.

11. Lowry, O. H., N. J. Rosebrough, A. L. Farr, and R. J. Randall. Protein measurement with the Folin phenol reagent. J. biol. Chem. 1951, 193, 265.

12. Schubert, M. Chondromucoprotein. Fed. Proc. 1958, 17, 1099.

13. Collins, D. H. The Pathology of Articular and Spinal Diseases. New York, Williams and Wilkins, 1949.

14. Kaplan, D., and K. Meyer. Ageing of human cartilage. Nature (Lond.) 1959, 183, 1267.
15. Kuhn, R., and H. J. Leppelmann. Galaktosamin und Glucosamin im Knorpel in Abhängigkeit vom Lebensalter. Justus Liebigs Ann. Chem. 1958, 611, 254.

16. McElligott, T. F., and D. H. Collins. Chondrocyte function of human articular and costal cartilage compared by measuring the in vitro uptake of labelled $\left({ }^{35} \mathrm{~S}\right)$ sulphate. Ann. rheum. Dis. 1960 , 19, 31.

17. Collins, D. H., and G. Meachim. Sulphate ( $\left.{ }^{25} \mathrm{SO}_{4}\right)$ fixation by human articular cartilage compared in the knee and shoulder joints. Ann. rheum. Dis. 1961, 20, 117.

18. Thomas, L. Reversible collapse of rabbit ears after intravenous papain, and prevention of recovery by cortisone. J. exp. Med. 1956, 104, 245.

19. Meyer, K., and M. M. Rapport. Hyaluronidases. Advanc. Enzymol. 1952, 13, 199. 